\section{SOI: $1.1 /$ TAS DOI: $10.15863 / \mathrm{TAS}$ \\ International Scientific Journal Theoretical \& Applied Science}

p-ISSN: 2308-4944 (print) $\quad$ e-ISSN: 2409-0085 (online)

Year: $2015 \quad$ Issue: $05 \quad$ Volume: 25

Published: $30.05 .2015 \quad$ http://T-Science.org
Dmitry Igorevich Khakhalin

student of the 2nd course

Financial University under the Government of the Russian Federation (Kaluga Branch), Russia mitya.khakhalin@mail.ru

SECTION 31. Economic studies, Finance, innovation, risk management.

\title{
ANALYSIS OF INDICATORS OF ECONOMIC DEVELOPMENT IN RUSSIA IN 2009-2014
}

Abstract: In this paper, the dynamics of economic indicators in the Russian economy during the 2009-2014 period. It reflects the changes that have taken place in the economic structure, the ups and downs of growth indicators considered in the proposed time period.

Key words: The Russian economy, GDP, industrial production index, exchange rate, import, investments.

Language: Russian

Citation: Khakhalin DI (2015) ANALYSIS OF INDICATORS OF ECONOMIC DEVELOPMENT IN RUSSIA IN 2009-2014. ISJ Theoretical \& Applied Science 05 (25): 185-188.

Soi: http://s-o-i.org/1.1/TAS*05(25)36 Doi: crossef http://dx.doi.org/10.15863/TAS.2015.05.25.36

\section{АНАЛИЗ ПОКАЗАТЕЛЕЙ ЭКОНОМИЧЕСКОГО РАЗВИТИЯ РОССИИ В 2009-2014 ГОДЫ}

Аннотация: В данной статье рассмотрена динамика экономических показателей экономики России 8 период 2009-2014 г2. Отражены изменения, которые произошли в структуре экономики, подъемы и спады роста рассматриваемых показателей в предложенном временном периоде.

Ключевые слова: Экономика России, ВВП, индекс промышленного производства, курс валюты, импорт, инвестиции.

В свете последних политических событий, а также под влиянием санкций, российская экономика претерпевает серьезные изменения. Последствия экономического кризиса 2009 года серьезно ударили по экономике страны [9]. Так, в 2009 году уровень ВВП резко снизился, однако в течение 3-х последующих лет российская экономика не только наверстала объемы предыдущих периодов (докризисных), но и заметно превысила их. Данный вывод можно сделать исходя из данных таблицы 1.

Динамика уровня ВВП России за период 2008-2012 гг. в текущих ценах.

Таблица 1

\begin{tabular}{|c|c|c|c|c|c|}
\hline Годы & 2008 & 2009 & 2010 & 2011 & 2012 \\
\hline $\begin{array}{c}\text { Сумма, } \\
\text { млрд.руб. }\end{array}$ & 41276,8 & 38807,2 & 46308,5 & 55967,2 & 62176,5 \\
\hline
\end{tabular}

Источник: составлено автором по данным Федеральной службы государственной статистики [10].

Как происходило становление этих других экономических показателей? Рассмотрим как положительные, так и отрицательные динамики роста некоторых из них.

Для начала рассмотрим рост таких показателей как инвестиции в основной капитал и реальные доходы населения. Один из показателей экономического развития Российской Федерации, по которому в процессе исследования было выявлено улучшение значений - инвестиции в основной капитал. В 2010 г. их объем увеличился на 6\%, в 2011 г. обнаружен скачкообразный рост, составивший к концу года $8,2 \%$, но в 2012 г. рост немного

ISPC Industry \& Technology Europe, 
замедлился (по сравнению с 2011 годом) и был зафиксирован на отметке $6,7 \%$. Также хочется отметить рост такого немаловажного показателя как реальные доходы населения. Однако, у данного показателя были «и взлеты и падения»: в 2010 г. рост составил 5,1\%, однако в 2011 г. произошел, так сказать, сбой и рост составил 0,85\%, однако уже в 2012 г. все вернулось в позитивную динамику и рост составил 4,2\% [10].
Главная задача, которая стояла перед федеральными и региональными властями сократить уровень безработицы до докризисного. И с это задачей успешно получилось справиться.

Но не все показатели смогли выдержать положительной динамики роста. Их уровни роста в 2010-2011 годах стали заметно отличаться от тех, которые в итоге получились в 2012 году. Рассмотрим данную проблему на примере показателей, представленных в таблице 2 .

Таблица 2

Динамика некоторых экономических показателей за период 2010-2012 гг., в \% к предыдущему году.

\begin{tabular}{|l|c|c|c|}
\hline \multicolumn{1}{|c|}{ Показатель } & 2010 & 2011 & 2012 \\
\hline Индекс промышленного производства & 8,2 & 4,7 & 2,4 \\
\hline Строительство & 5,0 & 5,0 & 2,4 \\
\hline Грузооборот транспорта & 6,9 & 3,4 & 1,7 \\
\hline
\end{tabular}

Источник: составлено автором по данным Федеральной службы государственной статистики[10].

Исходя из данных таблицы 2 видно, что изза нехватки инвестиционных фондов не происходила модернизация оборудования и инфраструктуры. В следствие увеличения износа и устаревания техники рост в данных сферах стал замедляться, а в некоторых случаях начинает подходить к нулю.

Также, положительную динамику показали такие показатели как внешнеторговый оборот, экспорт и импорт. За период 2010-2011 годов они демонстрировали высокие темпы роста - 30\%. Однако, в 2012 году рост составил всего 3\%. Но этому есть объяснение. В период тотального роста этих показателей цена за баррель нефти начала увеличиваться с 65 до 110 долларов, тем самым перемахнув стоимость баррели в докризисный период в 95 долларов. А уже в 2012 году цена стабилизировалась и резких скачков не наблюдалось.

В исследуемом периоде (2010-2012 гг.) темпы роста ВВП Российской Федерации превышали среднемировой. Так, среднемировой уровень роста составлял около $3 \%$, в то время как российский ВВП демонстрировал рост на уровне 4\%. Также уровень ВВП развитых стран оказался в несколько раз меньше нашего. Своеобразный рекорд же принадлежит странам с развивающейся экономикой, уровень роста ВВП которых составил порядка 5\% [10].

После кризиса 2009 года прошло три года. За это время экономика России стабилизировалась и с уверенностью вошла в 2013 год. Однако этот год приготовил для российской экономики новые испытания, которые усложняются до настоящего времени.
Если говорить в целом о экономических показателях 2013 года, то экономика России начинала медленно, но уверенно, входить в состояния остановки роста. Так по данным Росстата уровень ВВП увеличился всего на 1,3\%. Это крайне низкий показатель, так как изначально прогнозировался темп $3,5 \%$. Практически остановился рост промышленности - он был равен 0,3\%. Практически впервые за последние 3 года показатели стали показывать отрицательные темпы роста. Например, грузооборот железнодорожного - темп роста $1,2 \%$. Такой же отрицательный рост был у экспорта. И что хуже всего, инвестиции стали утекать из страны - отрицательный рост в размере $-0,3 \%$ ) [10].

Если соединить все экономические показатели воедино и посмотреть на их темпы роста, то определенно можно сказать только одно - экономика России входит в состояние стагнации. И все это происходило при стремительно набирающей рост инфляции. Ее рост составил с 5,1\% в 2012 году до $6,8 \%$ в 2013 году [10].

В первом полугодии 2014 г. социальноэкономическая ситуация в Российской Федерации ухудшилась, особенно после принятия США и рядом других государств экономических санкций в отношении нашего государства и, в свою очередь, ответные санкции со стороны нашего государства. То каким образом наша экономика отразила на себе это санкционное влияние можно увидеть в таблице 3. 
Экономические показатели России в 2014 году, в \% к предыдущему году.

\begin{tabular}{|l|c|}
\hline \multicolumn{1}{|c|}{ Показатель } & 2014 \\
\hline ВВП & 0,8 \\
\hline Индекс выпуска товаров и услуг & 0,2 \\
\hline Внешнеторговый оборот & $-0,7$ \\
в том числе: & $-5,1$ \\
\hline Импорт & $-2,5$ \\
\hline Инвестиции & \\
\hline
\end{tabular}

Источник: составлено автором по данным Федеральной службы государственной статистики[10].

2014 год стал по истине сокрушительным для российской экономике. В этот период заметно снизился фондовый рынок - рыночная капитализация основных компаний России, рекордно сильным оказался спад национальной валюты по отношению к доллару и евро [8]. Курс рубля упал более чем на 20\%. При этом, инфляция намного ускорилась: по оценкам экспертов Росстата по состоянию на конец 2014 года темп увеличения индекса потребительских цен составил $11,4 \%$. Все эти факторы в общей совокупности привели к стагфляции.

Какой вывод можно сделать из сложившийся ситуации? Состояние экономики России заставляет задуматься многих политиков $u$ экономистов нашей страны, низкие уровни роста и высокие уровни отрицательных экономических показателей. Стагнация и стагфляция - главные проблемы, решение которых требует от российской экономики решительных шагов $к и х$ устранению.

Может возникнуть вопрос: «Была ли возможность каким-либо образом избежать столь губительного сокращения темпов роста экономических показателей?» Возможно. Как один из вариантов стоит рассматривать тот момент, что произошла, так называемая, инвестиционная пауза - момент, когда крупные проекты реализовались, а новые не успели начаться. Если бы произошло своевременное прогнозирование и реагирование на замедление экономики, то были бы приняты все меры для устранения всех неполадок функционирования и сейчас можно было бы не слышать в экономических кругах этих терминов - стагнация и стагфляция.

Главной надеждой современной экономики являются инвестиции. Важно помнить, что, инвестируя сейчас, мы вкладываем деньги в будущее. Однако, если обратиться к статистике, то можно увидеть, что в кризис инвестиции сократились на $15 \%$ [10]. На восстановление прежних объемов ушло три года, однако уже в 2013 году рост прекратился, и в 2014 году объем инвестиций вновь стал сокращаться.

Отток капитала является экономическим якорем, который тормозит экономику любого государства. В течение 2009 - 2010 годов экспорт снизился на 234 млрд. долл. Также по причине падения цен на нефть и газ за аналогичный период из резервного фонда было изъято порядка 4,6 трлн. руб. для восполнения ниш в бюджете. За время кризиса золотовалютные резервы сократились на 211 млрд. долл. Если суммировать отток капитала за период с 2008 по 2014 гг. то он будет равен 0,5 трлн. долл [10].

Вышеизложенные проблемы повлекли за собой недофинансирование экономического роста. В период до кризиса 2009 года экономический рост поддерживался средствами из бюджета и за счет увеличения объемов кредитов для предприятий. Немаловажным фактом является то, что в период 2006 - 2007 гг. в страну было привлечено около 125 млрд. долл [10]. Это было обусловлено увеличением прибыльности предприятий и подъемом экономики. Что же мы наблюдаем в кризисный период? Масштабный отток капитала, увеличение как расходов бюджетов организаций, так и увеличение процентной ставки по кредитам - все это пагубно повлияло на состояние экономики страны. Как результат всего этого в 2013 году вылились низкие темпы роста прибыли и сокращение прибыли за вычетом убытка. Данная тенденция остается актуальной по сей день.

Инвесторы не видят необходимости оставлять свои капиталы в убыточных организациях. Корпоративный долг предприятий составляет немалую часть общего внешнего долга России. Под воздействием многих факторов общий внешнеэкономический долг с 2010 по январь 2014 года вырос с 467 млрд. долл. до 732 млрд. долл [7]. Введение санкций - одна из преград для частичной компенсации возвратных сумм.

Важной причиной отставания отечественной экономики на современном ее этапе является устаревание активной части основных фондов (имеется ввиду машины и оборудование). Недостаток инвестиций не дал возможности обновить фонды в период 2008 - 2014 гг. Степень их износа выросла более чем на 50 \%. По этой 
причине возникает проблема сверх затрат на обслуживание старых фондов, а именно: текущий капитальный ремонт, увеличение затрат электроэнергии, понижение качества продукции и др.

Пожалуй, главная причина экономических проблем - сильная зависимость России как добывающей державы от цен на ее ресурсы, ведь добыча сырья, производства полупродуктов и материалов - все это является капиталоемкими отраслями. Наряду с транспортной составляющей экономики добывающие и обрабатывающие производства «забирают к себе» более половины инвестиций, а на такие отрасли как, например, жилищное строительство или развитие «экономики знаний», средств выделяется крайне мало.

Научное исследование выполнено под руководством Трутневой Н.Ю., к.э.н., ст. преподавателя кафедры «Экономика», Финансовый университет при Правительстве РФ (Калужский филиал), Россия.

\section{References:}

1. Avdeeva ES, Varapaeva VV (2014) Rossija i strany postsovetskogo prostranstva: sostojanie jekonomik i vneshnetorgovye svjazi v 2013 godu // Vestnik Povolzhskoj akademii gosudarstvennoj sluzhby. 2014. № 6 (45). pp. 24-33.

2. Balynin IV (2014) Rejtingovaja ocenka sub'ektov Rossijskoj Federacii po urovnju riska nesbalansirovannosti regional'nyh bjudzhetov (na osnove razrabotannoj modeli) // RISK: Resursy, informacija, snabzhenie, konkurencija. 2014. № 3. pp.104-109

3. Balynin IV (2015) Analiz makrojekonomicheskih pokazatelej regional'nogo razvitija sub\#ektov Rossijskoj Federacii v 2008-2012 godah // RISK: Resursy, informacija, snabzhenie, konkurencija. 2015. № 1. pp.124-127.

4. Balynin IV (2013) Kompleksnaja model' rejtingovoj ocenki sub\#ektov Rossijskoj Federacii po urovnju riska negativnogo kreditnogo vlijanija na regional'nye jekonomiki: teoreticheskij aspekt i prakticheskaja realizacija // Jekonomicheskie issledovanija. 2013. № 3. p. 5 .

5. Grinberg RS (2015) Jekonomika sovremennoj Rossii: sostojanie, problemy, perspektivy //
Vestnik Instituta jekonomiki RAN. 2015. № 1. pp. 10-29.

6. Minakov AV (2013) Razvitie jekonomiki i sostojanie bjudzhetnonalogovoj sistemy Rossii // Nauchno-issledovatel'skij finansovyj institut. Finansovyj zhurnal. 2013. № 2 (16). pp. 123130.

7. (2015) Vneshnij dolg Rossii: [Jelektronnyj resurs], 2001-2015. Available: https://ru.wikipedia.org/wiki/\%C2\%ED\%E5\%F 8\%ED\%E8\%E9 \%E4\%EE\%EB\%E3 \% $\%$ DE E\%F1\%F1\%E8\%E8 (Accessed: 28.05.2015)

8. (2015) Evro dostig 100 rublej: [Jelektronnyj resurs], 1991-2015. Available: http://www.interfax.ru/business/413376

(Accessed: 29.05.2015)

9. (2015) Perezagruzka jeksportnoj modeli: [Jelektronnyj resurs], 1995-2014. Available: http://expert.ru/expert/2012/32/perezagruzkaeksportnoj-modeli/ (Accessed: 29.05.2015)

10. (2015) Federal'naja sluzhba gosudarstvennoj statistiki: [Jelektronnyj resurs] 1999 - 2014. Available: http://www.gks.ru (Accessed: 28.05.2015) 